\title{
METODOLOGIAS DE APRENDIZAGEM SIGNIFICATIVAS NO ENSINO FARMACÊUTICO: UMA REVISÃO INTEGRATIVA
}

\author{
Nathalia Minelli Medeiros de Sousa, UFCG, nathalia-minelli@hotmail.com
}

\author{
RESUMO
}

O estudo trata-se de uma revisão integrativa que objetivou identificar quais as metodologias de aprendizagem significativas são mais utilizadas no ensino farmacêutico apontadas na literatura vigente. Os dados foram coletados nas bases de dados Scielo e BVS, com recorte temporal entre os anos 2008 e 2018, utilizando os descritores: "aprendizagem ativa", "educação em farmácia", "metodologias", assim a amostra constitui em 9 artigos. A partir dos estudos foi possível verificar que todas as metodologias empregadas são alternativas que proporcionam aos alunos a trabalhar com problemas reais e/ ou desafios que exigem momentos de reflexão, criatividade, habilidade comunicativa e exercício de liderança. Concluise que com a aplicação de metodologias de aprendizagem significativas no ensino farmacêutico o processo de aprendizagem torna-se reflexivo e proporciona ao educando enfrentar o seu cotidiano profissional de maneira mais eficaz, humanizada e capaz de prestar serviços voltados ao integral cuidado das pessoas.

PALAVRAS-CHAVE: Aprendizagem Ativa, Educação em Farmácia, Metodologias.

\section{SIGNIFICANT LEARNING METHODOLOGIES IN PHARMACEUTICAL TEACHING: AN INTEGRATING REVIEW}

\begin{abstract}
The study is an integrative review that aimed to identify which significant learning methodologies are most used in pharmacy teaching pointed out in the current literature. The data were collected in the scielo and vhl databases, with a temporal cut between 2008 and 2018, using the descriptors: "active learning", "pharmacy education", "methodologies", so the sample consisted of 9 articles. From the studies it was possible to verify that all the methodologies used are alternatives that allow students to work with real problems and / or challenges that require moments of reflection, creativity, communicative ability and leadership exercise. It is concluded that with the application of meaningful learning methodologies in pharmaceutical education, the learning process becomes reflexive and allows the student to face his professional life in a more efficient, humanized way and able to provide services aimed at the integral care of people.
\end{abstract}

KEYWORDS: Active Learning, Pharmacy Education, Methodologies.

METODOLOGÍAS DE APRENDIZAJE SIGNIFICATIVAS EN LA ENSINA FARMACÉUTICA: UNA REVISIÓN INTEGRATIVA 


\section{RESUMEN}

El estudio se trata de una revisión integrativa que objetivó identificar cuáles las metodologías de aprendizaje significativas son más utilizadas en la enseñanza farmacéutica apuntadas en la literatura vigente. Los datos fueron recolectados en las bases de datos scielo y bvs, con recorte temporal entre los años 2008 y 2018, utilizando los descriptores: "aprendizaje activo", "educación en farmacia", "metodologías", así la muestra constituye en 9 artículos. A partir de los estudios fue posible verificar que todas las metodologías empleadas son alternativas que proporcionan a los alumnos a trabajar con problemas reales y / o desafíos que exigen momentos de reflexión, creatividad, habilidad comunicativa y ejercicio de liderazgo. Se concluye que con la aplicación de metodologías de aprendizaje significativas en la enseñanza farmacéutica el proceso de aprendizaje se vuelve reflexivo y proporciona al educando enfrentar su cotidiano profesional de manera más eficaz, humanizada y capaz de prestar servicios orientados al integral cuidado de las personas.

PALABRAS CLAVES: Aprendizaje Activo, Educación en Farmacia, Metodologías. 


\section{INTRODUÇÃO}

Ao longo dos anos várias mudanças vêm ocorrendo no setor econômico, social e político, o que tem ocasionado diversas transformações no processo educativo impondo diversos desafios e problemas que precisam ser superados para que esse processo de fato se concretize.

O sistema educacional tem como objetivo principal auxiliar o desenvolvimento dos cidadãos, para que possam respeitar as diversidades e participar de diversos grupos sociais, já que os indivíduos não vivem isoladamente e necessitam serem atores da sua própria história.

A educação, portanto constitui-se de um projeto de humanização que transforma o indivíduo a partir do seu perfil biológico e sócio cultural, já que a educação vai além da aquisição de conhecimentos, sendo a ponte que interliga o sujeito à sociedade.

A característica principal da educação é o deslocamento do enfoque individual para o enfoque social, político e ideológico. Assim, novas propostas educativas surgem diante da realidade e as atualizações das metodologias educacionais emergem diante disso. Nessa perspectiva, a educação ocorre durante a vida inteira, sendo pautada em quatro pilares norteadores: aprender a conviver, aprender a conhecer, aprender a fazer, aprender a ser (GADOTTI, 2000).

No cenário atual em que vivemos surge um novo modelo de ensino pautado no uso de metodologias interativas e construtivistas como disparadoras de aprendizagem e mudança de práticas. Assim, surge o método de ensino aprendizagem que estimula o aluno a pensar criticamente e permite a construção do conhecimento a partir da realidade, a fim de agregar o conhecimento prévio dos alunos e romper com o paradigma que o docente é o detentor de todo o conhecimento, e que é possível aprender simultaneamente.

Nesse contexto, o professor é o mediador do processo ensino aprendizagem que deve proporcionar e intermediar a busca pelo conhecimento, a partir de uma orientação adequada, para isso dentre a variedade de metodologias disponíveis o mesmo deve escolher aquela que melhor se adapta a disciplina e a fase do curso.

Diante desse cenário o aluno/farmacêutico em formação deve ser o sujeito ativo do processo ensino-aprendizagem, que pensa, interage e intervêm de forma ampla para a promoção, prevenção e recuperação da saúde, favorecendo a melhoria da qualidade de 
vida das pessoas. Para isso, se faz necessário que durante sua formação acadêmica o mesmo seja preparado para atuar ativamente visando uma formação holística, humanizada e critica-reflexiva.

Nessa perspectiva, este estudo adotou a seguinte questão norteadora "identificar quais as metodologias de aprendizagem significativas são mais utilizadas no ensino farmacêutico apontadas na literatura vigente?". Dessa forma, analisa-se aqui, as metodologias de ensino aprendizagem significativas na educação farmacêutica a partir de uma revisão integrativa da literatura, com os objetivos específicos: i) identificar quais as metodologias de aprendizagem significativas são utilizadas no ensino farmacêutico; ii) determinar os benefícios do uso das metodologias significativas de ensino aprendizagem no processo de formação do aluno/farmacêutico; iii) identificar como o uso dessas metodologias pode contribuir para a prática profissional qualificada e humanizada voltada ao integral cuidado das pessoas.

As metodologias significativas de ensino aprendizagem baseiam-se em estratégias que trazem como disparador de aprendizagem problemas reais ou construídos ilustrativamente, mas com ênfase na realidade, visando às condições de solucionar, com sucesso, desafios advindos das atividades essenciais da prática social em diferentes contextos.

A aprendizagem significativa busca através do conhecimento prévio dos alunos a formação satisfatória e com qualidade, fazendo-os descobrir e redescobrir novos conhecimentos e significados pertinentes (COSTA, 2013).

A utilização de metodologias e estratégias que favoreçam o desenvolvimento de alunos reflexivos, participativos, comprometidos com o coletivo, é necessária para que a educação possa contribuir com a transformação social (TONIETO; FÁVERO, 2012).

Assim, é possível trabalhar com metodologias ativas em todos os níveis de ensino, de maneira a proporcionar um ensino colaborativo proporcionando o desenvolvimento de competências, atitudes capazes de proporcionar uma aprendizagem significativa a partir de vários saberes compartilhados. 


\section{MÉTODO}

Trata-se de uma revisão integrativa da literatura, de caráter exploratório, que faz uma interface das metodologias de ensino aprendizagem significativas no ensino farmacêutico. Dessa forma, foram adotadas as seguintes etapas para a constituição da revisão integrativa: 1) seleção da pergunta da pesquisa; 2) definição dos critérios de inclusão de estudos e seleção da amostra; 3 ) representação dos estudos selecionados em forma de tabela; 4) análise dos achados; 5) interpretação dos resultados e 6) reportar, de forma, a evidência encontrada.

O percurso metodológico incluiu primeiramente o levantamento bibliográfico, por meio do qual se realizou uma pesquisa exploratória e integrativa por meio eletrônico nas seguintes bases de dados: Scientific Electronic Library Online (Scielo) e Biblioteca Virtual em Saúde (BVS).

Foram identificados 23 estudos nas bases de dados abordadas, sendo 21 da Scielo e 2 da BVS. Os critérios de inclusão foram: i) recorte temporal 2008 a 2018, ii) texto integral disponível em formato eletrônico, gratuito e supracitado em português ou inglês; iii) presença do termo de busca "aprendizagem ativa", "educação em farmácia", "metodologias".

A partir dos resultados da busca, foi executado o trabalho de eliminação de artigos não correlatos à temática em estudo, artigos não disponíveis de forma gratuita na íntegra e duplicidades. Após uma análise minuciosa, nove (9) se adequavam aos critérios de inclusão, compondo a amostra final desta revisão integrativa (Figura 1). 
Figura 1:- Fluxograma do processo de seleção dos estudos identificados e selecionados segundo a base de dados.

\begin{tabular}{|c|}
\hline Estudos \\
identificados nas \\
bases de dados \\
\hline Seleção por meio \\
dos critérios de \\
exclusão e \\
inclusão \\
\hline Total de arquivos \\
incluídos na \\
amostra - leitura \\
na integra
\end{tabular}

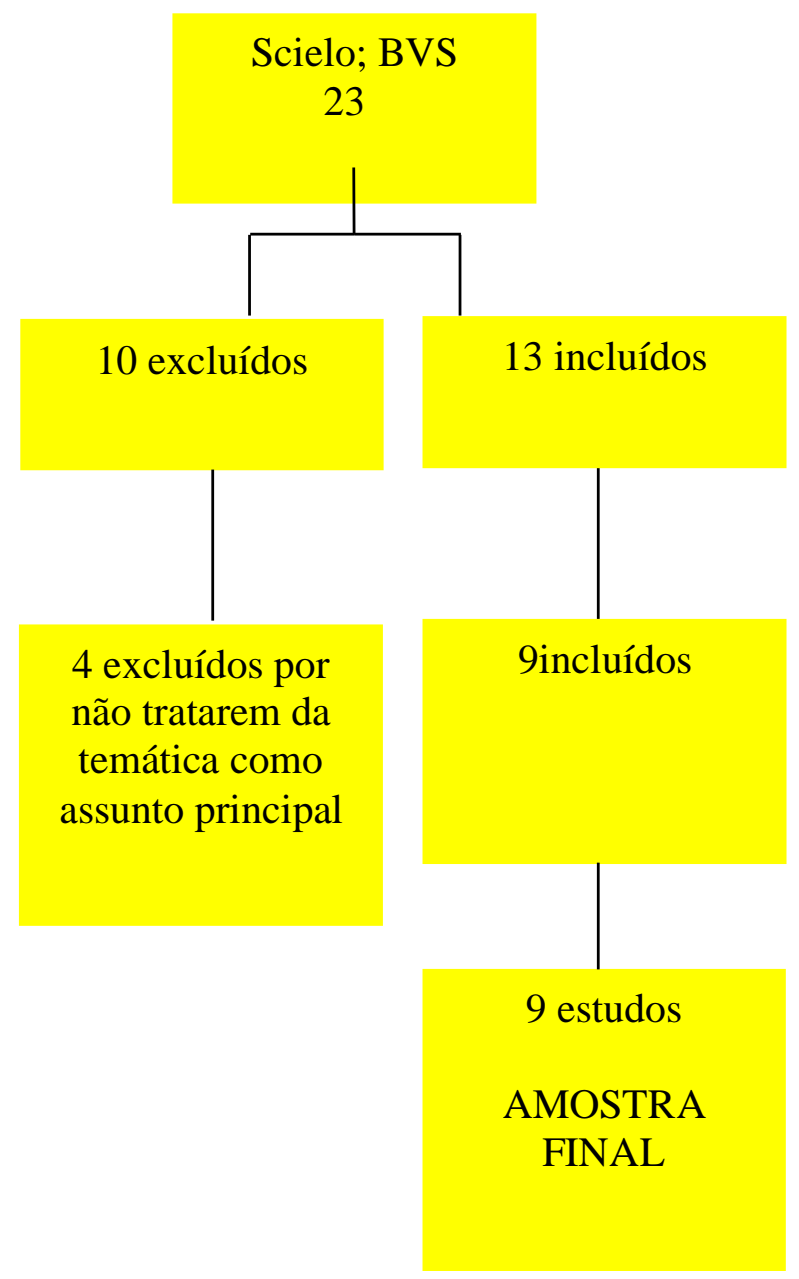

Fonte: Elaboração própria. 


\section{RESULTADOS E DISCUSSÃO}

$\mathrm{Na}$ amostra coletada, observou-se o uso de metodologias ativas de ensino como ferramenta de aprendizagem na educação farmacêutica, isso vem de encontro com as novas mudanças na formação de profissionais na área da saúde.

Os estudos incluídos na revisão foram analisados de forma sistemática apresentando as principais informações de cada pesquisa: títulos, autores, periódicos e dados do artigo, objetivos, métodos e resultados (Quadro 1). literatura.

Quadro 1: Sistematização dos artigos selecionados para a revisão integrativa da

\begin{tabular}{|c|c|c|c|c|}
\hline Título & Autor(es) & $\begin{array}{l}\text { Periódicos e } \\
\text { dados do } \\
\text { artigo }\end{array}$ & Objetivos & Resultados \\
\hline $\begin{array}{l}\text { Exame } \\
\text { Clínico } \\
\text { Objetivo } \\
\text { Estruturado } \\
\text { (ECOE): uma } \\
\text { experiência } \\
\text { de ensino por } \\
\text { meio de } \\
\text { simulação do } \\
\text { atendimento } \\
\text { farmacêutico. }\end{array}$ & GALATO et al. & $\begin{array}{l}\text { Interface - } \\
\text { Comunicação } \\
\text { Saúde } \\
\text { Educação. } \\
\text { 2011; 15(36): } \\
\text { 309-19. }\end{array}$ & $\begin{array}{l}\text { Apresentar a } \\
\text { experiência de } \\
\text { ensino no curso } \\
\text { de Farmácia da } \\
\text { Unisul } \\
\qquad \text { no } \\
\text { processo de } \\
\text { ensino- } \\
\text { aprendizagem } \\
\text { por meio da } \\
\text { simulação } \\
\text { atendimento } \\
\text { farmacêutico } \\
\text { (ECOE). }\end{array}$ & $\begin{array}{l}\text { Essa atividade } \\
\text { possibilitou } \\
\text { identificação dos } \\
\text { erros, que muitas } \\
\text { vezes, podem refletir } \\
\text { lacunas de } \\
\text { conhecimento ou } \\
\text { falta de habilidades. } \\
\text { (...) O ECOE } \\
\text { permite ao } \\
\text { acadêmico deixar de } \\
\text { lado a ansiedade e } \\
\text { focar sua atenção na } \\
\text { melhoria de suas } \\
\text { habilidades. (...) Para } \\
\text { os professores } \\
\text { tutores do ECOE } \\
\text { trata-se de uma } \\
\text { experiência bastante }\end{array}$ \\
\hline
\end{tabular}




\begin{tabular}{|c|c|c|c|c|}
\hline & & & & $\begin{array}{l}\text { intensa e, portanto, o } \\
\text { conduz ao } \\
\text { aprendizado. }\end{array}$ \\
\hline $\begin{array}{l}\text { Avaliação } \\
\text { discente sobre } \\
\text { a metodologia } \\
\text { de ensino } \\
\text { baseado em } \\
\text { problemas na } \\
\text { disciplina de } \\
\text { Farmacologia. }\end{array}$ & $\begin{array}{l}\text { SANTANA; } \\
\text { CUNHA; SOARES. }\end{array}$ & $\begin{array}{l}\text { Revista } \\
\text { Brasileira de } \\
\text { Farmácia. } \\
\text { 2012; } 93 \text { (3): } \\
\text { 337-340. }\end{array}$ & $\begin{array}{l}\text { Identificar o nível } \\
\text { de aceitação da } \\
\text { metodologia } \\
\text { ativa de ensino } \\
\text { por acadêmicos } \\
\text { de cursos de } \\
\text { nível superior na } \\
\text { área de saúde da } \\
\text { Universidade de } \\
\text { Fortaleza } \\
\text { utilizando a } \\
\text { Doença } \\
\text { Parkinson como } \\
\text { uma ferramenta } \\
\text { de discussão. }\end{array}$ & 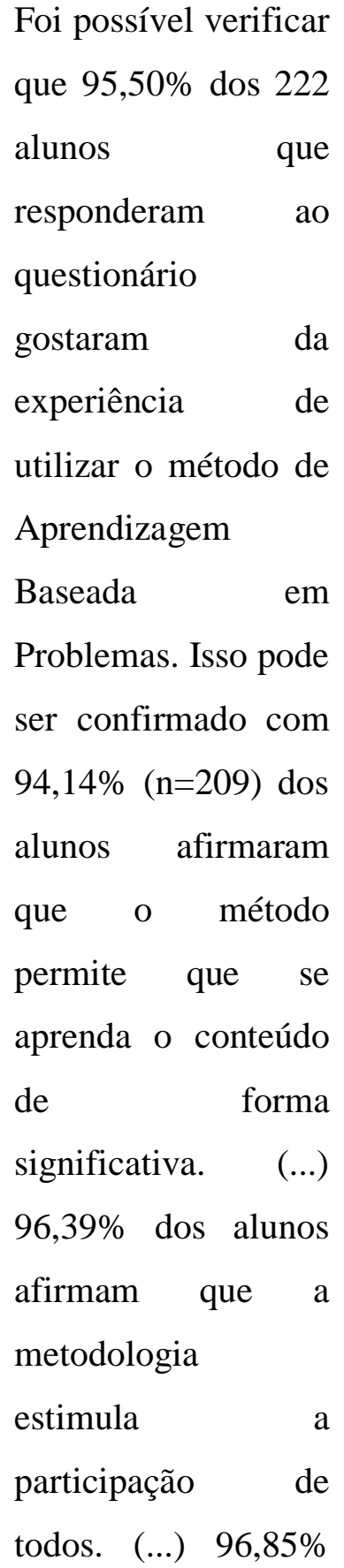 \\
\hline
\end{tabular}




\begin{tabular}{|c|c|c|c|c|}
\hline & & & & 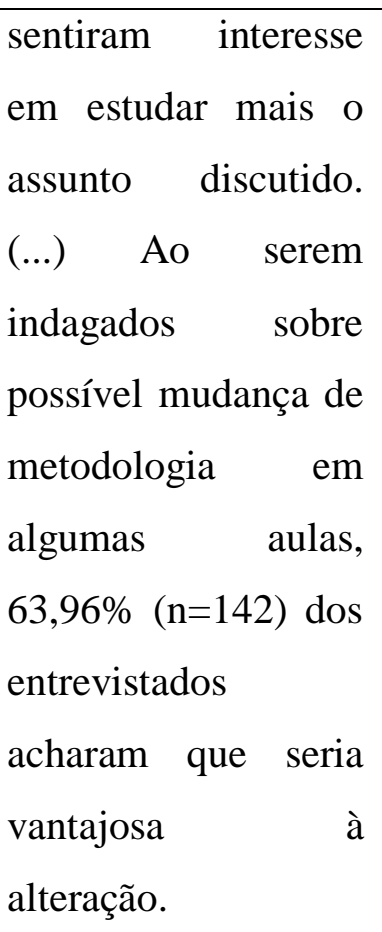 \\
\hline $\begin{array}{l}\text { Metodologias } \\
\text { ativas de } \\
\text { ensino- } \\
\text { aprendizagem } \\
\text { para a } \\
\text { educação } \\
\text { farmacêutica: } \\
\text { um relato de } \\
\text { experiência. }\end{array}$ & LIMBERGER JB & $\begin{array}{l}\text { Interface- } \\
\text { Comunicação } \\
\text { Saúde } \\
\text { Educação. } \\
2013 \text {; } \\
\text { 17(47):969- } \\
75 .\end{array}$ & $\begin{array}{l}\text { Abordar o uso de } \\
\text { metodologias } \\
\text { ativas de ensino- } \\
\text { aprendizagem na } \\
\text { disciplina de } \\
\text { Assistência e } \\
\text { Atenção } \\
\text { Farmacêutica do } \\
\text { curso } \\
\text { Farmácia } \\
\text { Centro do } \\
\text { Universitário } \\
\text { Franciscano } \\
\text { (Unifra), } \\
\text { relatando } \\
\text { avanços } \\
\text { dificuldades } \\
\text { observadas. }\end{array}$ & 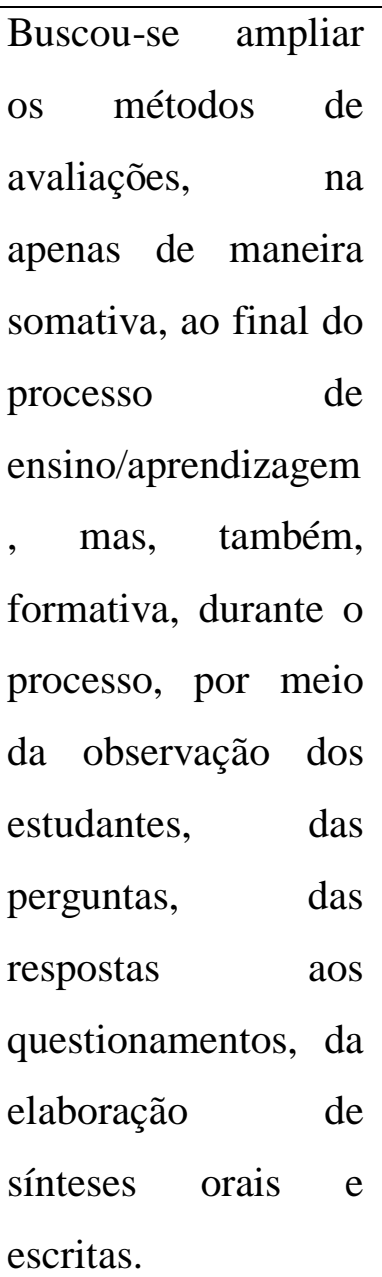 \\
\hline
\end{tabular}




\begin{tabular}{|c|c|c|c|c|}
\hline $\begin{array}{l}\text { Avaliação da } \\
\text { experiência } \\
\text { de estudantes } \\
\text { de farmácia } \\
\text { no } \\
\text { componente } \\
\text { curricular de } \\
\text { farmacologia } \\
\text { com } \\
\text { utilização de } \\
\text { metodologia } \\
\text { de } \\
\text { aprendizagem } \\
\text { baseada em } \\
\text { tarefas. }\end{array}$ & CRISTINE DC & $\begin{array}{l}\text { Foco. } 2013 ; 4 \\
(5): 89-110 .\end{array}$ & $\begin{array}{l}\text { Avaliar } \\
\text { implantação da } \\
\text { metodologia } \\
\qquad \text { PBL na } \\
\text { disciplina de } \\
\text { Farmacologia do } \\
\text { curso de } \\
\text { Farmácia das } \\
\text { Faculdade } \\
\text { Integradas } \\
\text { Maria Imaculada, } \\
\text { localizada na } \\
\text { cidade } \\
\text { de Mogi } \\
\text { Guaçu, Estado de } \\
\text { São Paulo. }\end{array}$ & 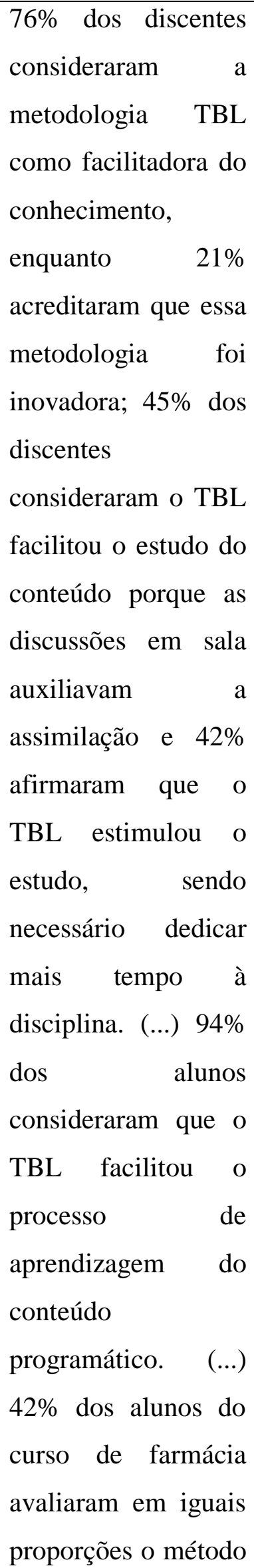 \\
\hline
\end{tabular}




\begin{tabular}{|c|c|c|c|c|}
\hline & & & & $\begin{array}{l}\text { TBL como } \\
\text { proveitoso, eficaz e } \\
\text { promotor } \\
\text { interação. }\end{array}$ \\
\hline $\begin{array}{l}\text { Metodologia } \\
\text { ativa na } \\
\text { construção de } \\
\text { um processo } \\
\text { educativo } \\
\text { crítico } \\
\text { reflexivo com } \\
\text { discentes do } \\
\text { curso de } \\
\text { farmácia. }\end{array}$ & BARROS et al. & $\begin{array}{l}\text { Revista } \\
\text { Expressão } \\
\text { Católica. } \\
\text { 2014; 3(1): } \\
\text { 53-60. }\end{array}$ & $\begin{array}{l}\text { Relatar } \\
\text { desenvolvimento } \\
\text { de um processo } \\
\text { crítico reflexivo } \\
\text { com os discentes } \\
\text { do curso de } \\
\text { graduação em } \\
\text { Farmácia de uma } \\
\text { faculdade privada } \\
\text { do Ceará, por } \\
\text { meio } \\
\text { utilização } \quad \text { do } \\
\text { Arco } \\
\text { Maguerez. }\end{array}$ & 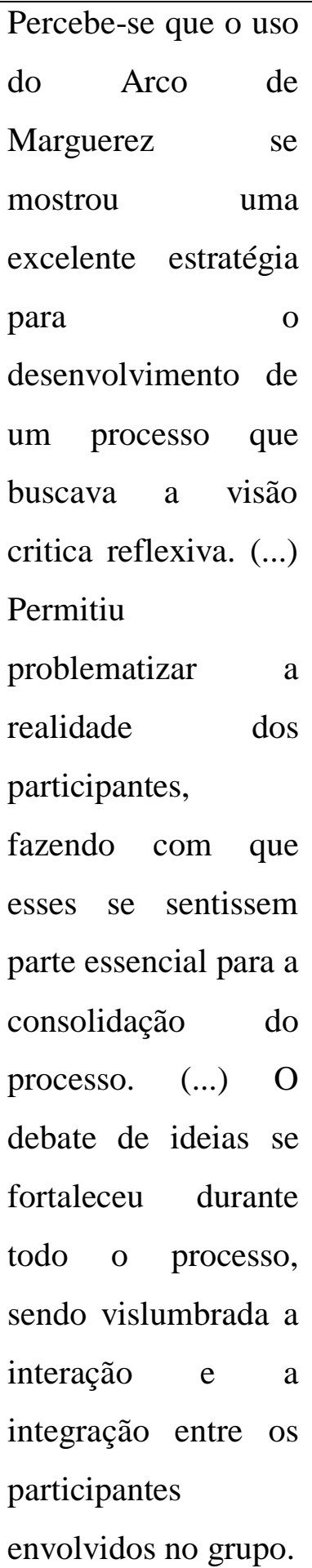 \\
\hline
\end{tabular}




\begin{tabular}{|c|c|c|c|c|}
\hline $\begin{array}{l}\text { Estudo } \\
\text { comparativo } \\
\text { da } \\
\text { metodologia } \\
\text { ativa } \\
\text { “gincana" nas } \\
\text { modalidade } \\
\text { presencial e à } \\
\text { distância em } \\
\text { curso de } \\
\text { graduação de } \\
\text { Farmácia. }\end{array}$ & $\begin{array}{l}\text { GOSSENHEIMER; } \\
\text { CARNEIRO; } \\
\text { CASTRO }\end{array}$ & $\begin{array}{l}\text { ABCS } \\
\text { Arquivos } \\
\text { Brasileiros de } \\
\text { Ciências da } \\
\text { Saúde. 2015; } \\
40 \text { (3): } 234- \\
240 .\end{array}$ & $\begin{array}{l}\text { Realizar uma } \\
\text { análise } \\
\text { comparativa da } \\
\text { atividade } \\
\text { "Gincana" nas } \\
\text { modalidades } \\
\text { presencial e a } \\
\text { distância. }\end{array}$ & 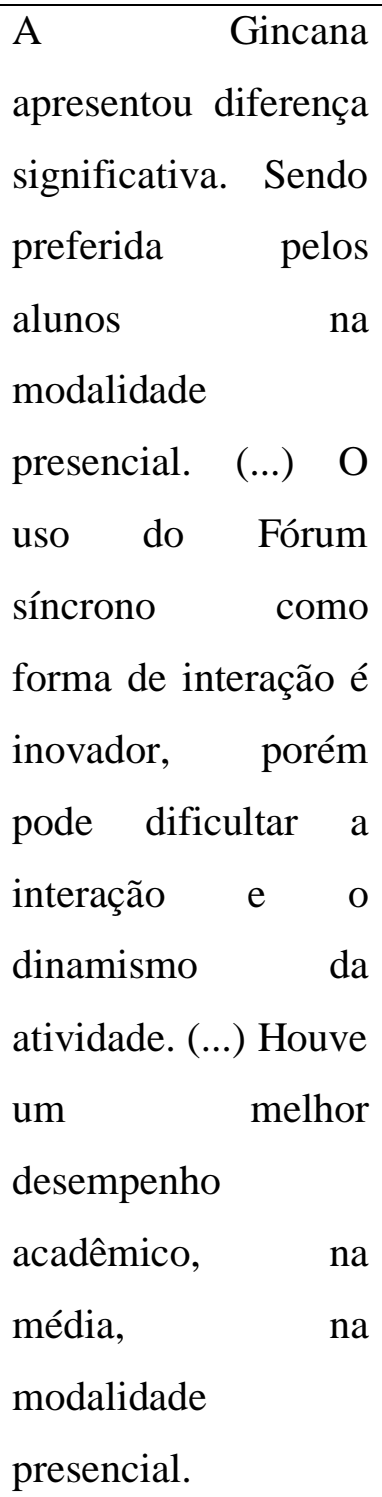 \\
\hline $\begin{array}{l}\text { Construção de } \\
\text { webblog } \\
\text { como } \\
\text { ferramenta } \\
\text { para o ensino } \\
\text { do uso } \\
\text { racional de } \\
\text { medicamentos } \\
\text { no curso de } \\
\text { farmácia da } \\
\text { Faculdade da }\end{array}$ & FAl & $\begin{array}{l}\text { Revista } \\
\text { Docência no } \\
\text { Ensino } \\
\text { Superior. } \\
\text { 2016; 6(2): } \\
\text { 177-202. }\end{array}$ & $\begin{array}{l}\text { Descrever a } \\
\text { experiência de } \\
\text { construção } \\
\text { deweblog } \\
\text { como ferramenta } \\
\text { de ensino no } \\
\text { curso de } \\
\text { Farmácia. }\end{array}$ & $\begin{array}{l}\text { Com a utilização do } \\
\text { weblog do CEMED } \\
\text { permitiu } \\
\text { participação ativa e } \\
\text { responsável dos } \\
\text { estudantes em todo o } \\
\text { processo da } \\
\text { produção } \\
\text { informação, } \\
\text { iniciando-se com a } \\
\text { seleção do tema até a }\end{array}$ \\
\hline
\end{tabular}




\begin{tabular}{|c|c|c|c|c|}
\hline $\begin{array}{l}\text { Universidade } \\
\text { Federal de } \\
\text { Minas Gerais } \\
\text { (UFMG). }\end{array}$ & & & & 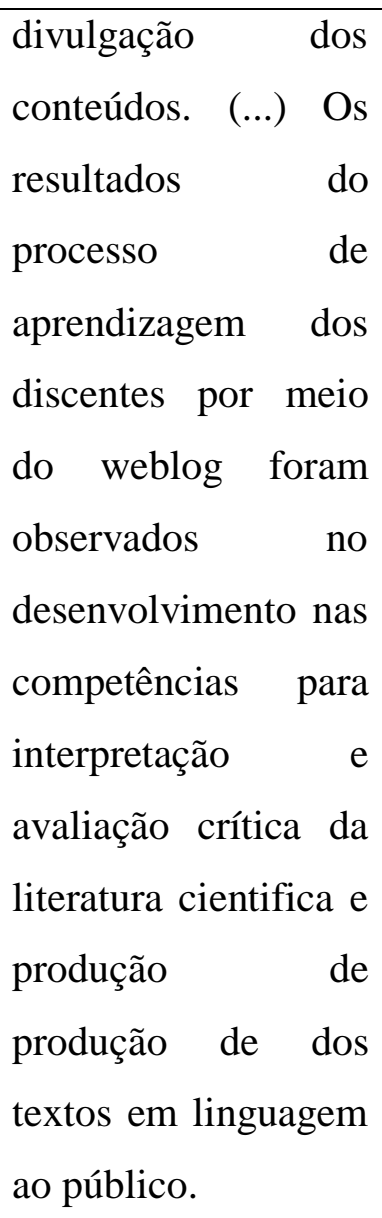 \\
\hline $\begin{array}{l}\text { A inclusão de } \\
\text { metodologias } \\
\text { ativas na } \\
\text { disciplina de } \\
\text { deontologia } \\
\text { farmacêutica } \\
\text { - relato de } \\
\text { experiência } \\
\text { docente. }\end{array}$ & $\begin{array}{l}\text { GUALBERTO; } \\
\text { VICENTE }\end{array}$ & $\begin{array}{l}\text { Revista de } \\
\text { Educação } \\
\text { Meio } \\
\text { Ambiente e } \\
\text { Saúde. 2017; } \\
\text { 7(2): 1-10. }\end{array}$ & $\begin{array}{l}\text { Relatar } \\
\text { experiência } \\
\text { docente da } \\
\text { utilização de } \\
\text { metodologias } \\
\text { ativas no ensino } \\
\text { da disciplina de } \\
\text { deontologia } \\
\text { farmacêutica. }\end{array}$ & $\begin{array}{l}\text { Com essa } \\
\text { experiência, foi } \\
\text { possível perceber } \\
\text { que a utilização da } \\
\text { tecnologia, através } \\
\text { de dispositivos em } \\
\text { sala de aula e uma } \\
\text { aplicação prática do } \\
\text { conteúdo ministrado } \\
\text { em forma de casos } \\
\text { clínicos, trabalhando } \\
\text { situações possíveis } \\
\text { da pratica } \\
\text { profissional } \\
\text { farmacêutica, }\end{array}$ \\
\hline
\end{tabular}




\begin{tabular}{|c|c|c|c|c|}
\hline & & & & $\begin{array}{l}\text { despertou mais } \\
\text { envolvimento } \\
\text { interesse } \\
\text { graduandos mesmo } \\
\text { por se tratar de } \\
\text { legislações extensas } \\
\text { e algumas vezes de } \\
\text { difícil compreensão. } \\
\text { (...) Conseguimos } \\
\text { fomentar, nas turmas } \\
\text { uma maior retenção } \\
\text { do conhecimento, } \\
\text { alcançando } \\
\text { objetivos os } \\
\text { capacitação dora } \\
\text { alunos na busca de } \\
\text { informação, } \\
\text { mantendo sempre a } \\
\text { interdisciplinaridade. }\end{array}$ \\
\hline $\begin{array}{l}\text { Metodologias } \\
\text { de ensino e os } \\
\text { estilos de } \\
\text { aprendizagem } \\
\text { na graduação } \\
\text { em farmácia: } \\
\text { um estudo } \\
\text { piloto. }\end{array}$ & JESUS et al. & $\begin{array}{l}\text { Revista } \\
\text { Online de } \\
\text { Política } \\
\text { Gestão } \\
\text { Educacional. } \\
\text { 2017; } 21 \text { (1): } \\
\text { 621-639. }\end{array}$ & $\begin{array}{l}\text { Avaliar a } \\
\text { aplicabilidade do } \\
\text { instrumento } \\
\text { Index of } \\
\text { Learning Styles } \\
\text { Questionnaire } \\
\text { (ILS) } \\
\text { identificar os } \\
\text { estilos de } \\
\text { preferências de } \\
\text { aprendizagem de } \\
\text { alunos do curso } \\
\text { de Farmácia da }\end{array}$ & $\begin{array}{l}\text { O estudo apontou } \\
\text { que não houve } \\
\text { diferença } \\
\text { significativa entre os } \\
\text { estilos de } \\
\text { aprendizagem de } \\
\text { estudantes } \\
\text { submetidos a } \\
\text { metodologias de } \\
\text { ensino diferentes. } \\
\text { (...) Em relação às } \\
\text { preferencias } \\
\text { individuais }\end{array}$ \\
\hline
\end{tabular}




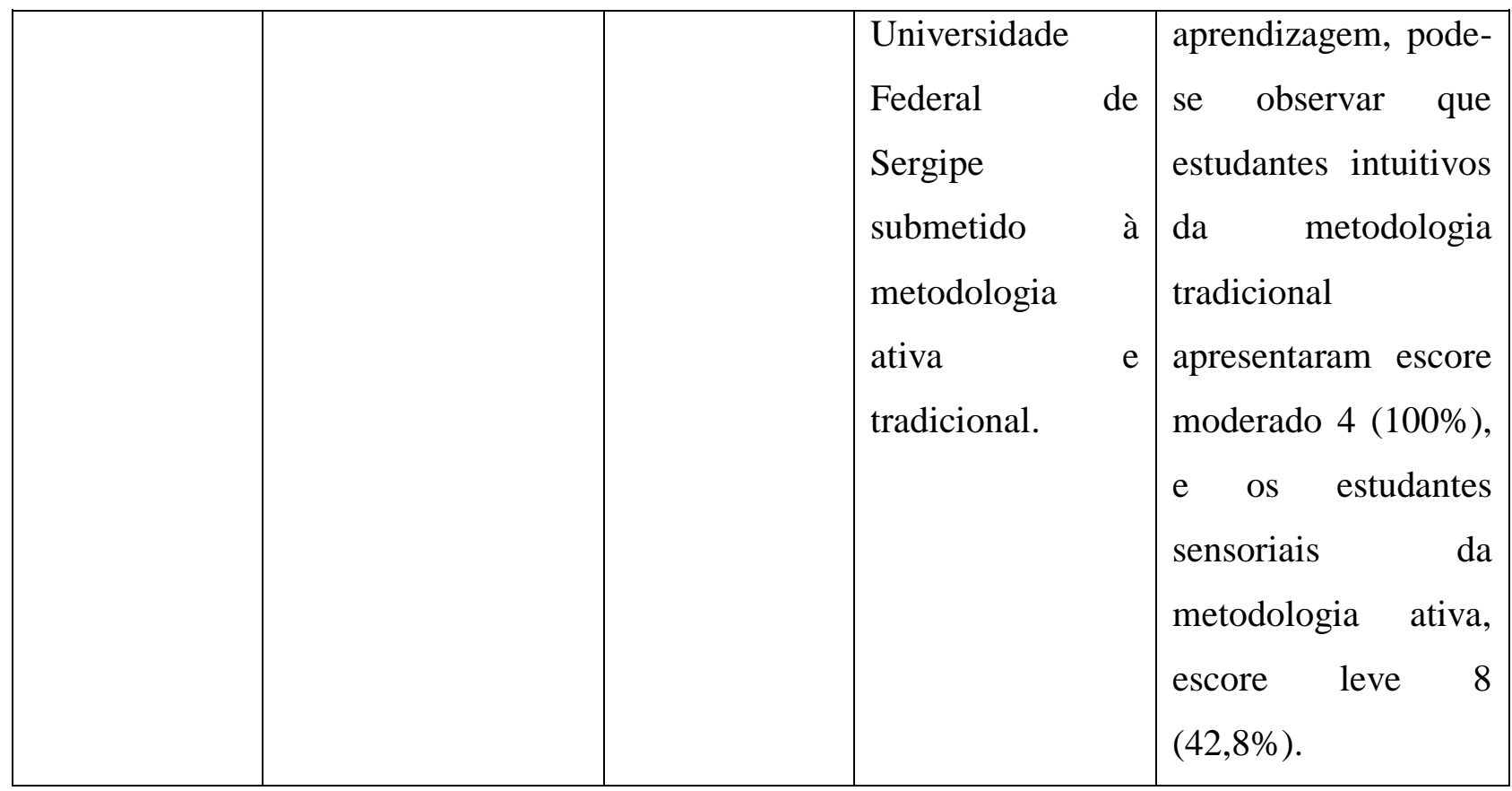

Fonte: Elaboração própria.

Foi possível verificar que a maioria dos autores é doutor 10 (28,57\%), 7 (20\%) são mestres, $9(25,71 \%)$ são especialistas e 9 (25,71\%) acadêmicos do curso de Farmácia.

Os estudos apresentam delineamentos de pesquisas de relatos de experiências, com abordagem metodológica descritiva, quantitativa e quantitativa. Também foi possível identificar que os estudos foram desenvolvidos nas regiões Nordeste $3(33,33 \%)$ , Sudeste $3(33,33 \%)$, com destaque para a cidade de Minas Gerais (67\%) e Sul 3 $(33,33 \%)$, realizado na sua maioria cidade do Rio Grande do Sul (67\%).

O ensino contemporâneo deve investir no processo de formação que supere o modelo de racionalidade técnica, por muito tempo norteador da organização de currículos e programas dos cursos universitários, constituindo-se em um espaço formador capaz de atender as demandas das sociedades globalizadas. Nesse contexto, o crescimento acelerado do conhecimento produzido, a complexidade do mundo do trabalho e fatores sociais e econômicos exigem profissionais autônomos capazes de buscar e criar conhecimentos na sua atuação profissional, diante disso faz-se necessário o repensar das metodologias de ensino (LIMBERGER, 2013).

Para Marini (2013) a aprendizagem abrange o crescimento e desenvolvimento da pessoa em sua totalidade, abarcando minimamente quatro grandes áreas: a do conhecimento, o efetivo emocional, a de habilidade e a de atitudes e valores. Esse 
modelo de aprendizagem envolve o estudante como pessoa, valorizando suas ideias, sentimento, valores, cultura sociedade e experiências pessoais. Essa preocupação de formar o estudante como um todo, ou seja, "formação profissional, pessoal e social" exige uma mudança significativa na educação superior da área da saúde que, historicamente, possui um forte enfoque tecnicista.

Com as mudanças nos paradigmas da profissão, viu-se a necessidade de reestruturação no ensino farmacêutico com o intuito de melhorar as habilidades clínicas dos acadêmicos, a fim de proporcionar uma formação holista, com profissionais reflexivos, proativos e que possam desenvolver competências necessárias para atuar de forma humanizada e serem capazes de enfrentar problemas complexos por meio do trabalho em equipe.

Tais considerações apontam que o papel do educador torna-se ainda mais desafiador, com a função de mediar o conhecimento a partir da elaboração de situações de ensino que promovam a aproximação critica do estudante coma realidade, a reflexão sobre problemas que geram curiosidade e desafio; a disponibilização de recursos para pesquisar; a identificação e organização das soluções hipotéticas mais adequadas e a aplicação dessas soluções de forma adequada (GUALBERTO; VICENTE, 2017).

Santana, Cunha e Soares (2012) contribuem com a discussão ao relatar que a implantação das metodologias ativas possui vários desafios dentre eles a mudança de cultura, a implantação institucional do projeto, a sensibilização e motivação da participação dos docentes e seu treinamento constante, a implantação de um processo de melhoria continuada com o professor assumindo o papel de facilitador, apoiando, envolvendo e promovendo a participação dos estudantes.

Tanto na amostra da pesquisa como na literatura, pode-se observar que o uso de metodologias ativas de ensino aprendizagem se configura como uma importante estratégia de ensino do profissional da saúde.

Foram identificadas diversas estratégias de aplicação dessas metodologias, nos artigos selecionados foram observados ao menos 9 tipos de operacionalização de metodologias ativas. O Quadro 2 descreve a metodologia e a respectiva referencia do artigo. 
Quadro 2: Tipos de metodologias de ensino aprendizagem

\begin{tabular}{|c|c|}
\hline Tipos & Referências \\
\hline Simulação de atendimento farmacêutico & $\begin{array}{l}\text { Interface - Comunicação Saúde Educação. } \\
\text { 2011; 15(36): 309-19. }\end{array}$ \\
\hline Aprendizagem baseada em problemas & $\begin{array}{l}\text { Revista Brasileira de Farmácia. 2012; } 93 \text { (3): } \\
\text { 337-340. }\end{array}$ \\
\hline Estudo de casos & $\begin{array}{l}\text { Interface- Comunicação Saúde Educação. } \\
\text { 2013; } 17 \text { (47):969-75. }\end{array}$ \\
\hline Aprendizagem baseada em tarefas & Foco. 2013; 4 (5): 89-110. \\
\hline Problematização: Arco de Marguerez & $\begin{array}{l}\text { Revista Expressão Católica. 2014; 3(1): 53- } \\
60 .\end{array}$ \\
\hline Dinâmica lúdico-pedagógica & $\begin{array}{l}\text { ABCS - Arquivos Brasileiros de Ciências da } \\
\text { Saúde. 2015; } 40 \text { (3): } 234-240\end{array}$ \\
\hline Blogs Educacionais & $\begin{array}{l}\text { Revista Docência no Ensino Superior. 2106; } \\
6(2): 177-202\end{array}$ \\
\hline Relato crítico de experiência & $\begin{array}{l}\text { Revista de Educação Meio Ambiente e Saúde. } \\
\text { 2017; 7(2): 1-10. }\end{array}$ \\
\hline Dramatizações & $\begin{array}{l}\text { Revista Online de Política e Gestão } \\
\text { Educacional. 2017; } 21 \text { (1): 621- 639 }\end{array}$ \\
\hline
\end{tabular}

Fonte: Elaboração própria.

Há diversas metodologias ativas de ensino aprendizagem utilizadas na educação farmacêutica, diante do estudo e das experiências relatadas nos artigos selecionados foram apontadas a validação e a significância do uso dessas metodologias.

Entende-se que todas as metodologias empregadas são alternativas que proporcionam aos alunos a trabalhar com problemas reais e/ou desafios que exigem momentos de reflexão, criatividade, habilidade comunicativos e exercício de liderança.

Este novo profissional exigido pelas últimas reformas curriculares dos cursos da área de saúde, e, em específico, o curso de Farmácia, tem perfil generalista, humanista, crítico e reflexivo, para atuar em todos os níveis de atenção à saúde, com base no rigor científico e intelectual (Brasil, 2002). 
Compreende-se a categoria de metodologias ativas como campo de aplicação de diferentes processos de ensino aprendizagem já bem definido, como a problematização, o Arco de Marguerez, estudos de casos clínicos, dramatizações, simulação de atendimento farmacêutico, dentre outros.

O educador pode criar diferentes espaços para proporcionar a aprendizagem com caráter dialético e de constante construção por aqueles que o fazem. Já que o ensino exige rigor metodológico, criticidade, ética, pesquisa e reflexão crítica sobre a pratica, assim é de suma relevância que o professor planeje sua atuação e que seja capaz de proporcionar uma educação problematizadora (FREIRE, 2008).

De acordo com o segundo e terceiro objetivos específicos desta pesquisa, verificou-se que com a aplicação das metodologias de aprendizagem ativas no processo de formação do aluno/farmacêutico foi possível despertar mais envolvimento e interesse dos graduandos, também foi eficaz no desenvolvimento de habilidades, competências, maior retenção do conhecimento e resolução de um problema do paciente.

Diante disso, é possível perceber que com a aplicação de metodologias ativas no ensino farmacêutico o processo de aprendizagem torna-se significativo e proporciona ao educando enfrentar o seu cotidiano profissional de maneira mais eficaz, humanizada e capaz de prestar serviços voltados ao integral cuidado das pessoas.

Essa discussão demonstra que embora haja a adesão do uso de metodologias que proporcione a aprendizagem significativa por parte de alguns docentes em algumas instituições de ensino, ainda é necessário à sua expansão para o avanço do processo educacional frente a novas práticas pedagógicas. 


\section{CONSIDERAÇÕES FINAIS}

Esta revisão analisou a proposta das metodologias de aprendizagem significativas no ensino farmacêutico, assim os estudos apresentados mostram diversas modalidades e estratégias positivas, sendo possível obter resultados motivadores, significativos e desafiadores com a aplicação dessas novas estratégias de ensino.

A utilização de metodologias ativas no ensino farmacêutico proporciona práticas inovadoras, momentos de reflexão frente às atividades propostas, além de habilidade de comunicação, exercício de participação e liderança. Exigindo sensibilização, motivação e a atuação do aluno de maneira ativa e reflexiva para mudanças na educação e na sociedade.

Por fim, o uso de metodologias de aprendizagem significativas leva o educando a um novo contexto educacional, em que ocorre uma mudança de paradigma em relação ao estudante e ao processo ensino aprendizagem.

Nessa perspectiva, espera-se que este estudo colabore com as discussões relativas sobre os novos métodos de ensino aprendizagem no ensino farmacêutico, elucidando os seus principais benefícios para a formação de profissionais criticoreflexivos, independentes e capazes de atuar favorecendo o processo de educação em saúde. 


\section{REFERÊNCIAS}

BARROS, K.B.N.T.; PRADO, R.M.S.; LOUREIRO, A.N.C.; VARELA, D.S.S.; BORGES, K. D.M.; MACHADO, M.F.A.S. Metodologia Ativa na Construção de um Processo Educativo Critico Reflexivo com Discentes do curso de Farmácia. InterfaceComunicação Saúde Educação. 2014; 17(47): 969-75.

BRASIL. Ministério da Educação. Resolução CNE/CES no 2, de 19 de fevereiro de 2002. Institui Diretrizes Curriculares Nacionais do Curso de Graduação em Farmácia.Brasília: MEC, 2002.

COSTA, V.C. I. Aprendizagem baseada em problemas (PBL).RevistaTavola Online. 5 (1): 1-3, $2013 . \quad$ mar., Disponível em: <http://nucleotavola.com.br/revista/2013/03/01/aprendizagem-baseada-em-problemaspbl/> .acesso em: 20 de fevereiro de 2019.

FARIA, J.C.M. Construção de weblog como ferramenta para o ensino do uso racional de medicamentos no curso de farmácia.. Revista Docência no Ensino Superior. 2016; 6(2): 177-202. Disponível em:https://periodicos.ufmg.br/index.php/rdes/article/view/2104. Acesso em 21 de fevereiro de 2019.

FREIRE, P. Pedagogia da autonomia: saberes necessários à prática educativa. 3 . ed.São Paulo: Paz e Terra; 2008.

GADOTTI, M. Perspectivas atuais da educação. São Paulo Perspectivas, 14(2), 2000. Disponível em: 〈http://www.scielo.br/pdf/spp/v14n2/9782.pdf>. Acesso: em 21 de fevereiro de 2019.

GAlATO, D.; ALANO, G.M.; FRANÇA, T. F.; VIEIRA, A.C. Exame Clínico Objetivo Estruturado (ECOE): uma experiência de ensino por meio de simulação do atendimento farmacêutico. Interface - Comunicação Saúde Educação. 2011; 15(36): 
309-19. Disponível em:〈http://www.scielo.br/pdf/icse/v15n36/aop3310.pdf $>$. Acesso em: 20 de fevereiro de 2019.

GOSSENHEIMER, A. N.; CARNEIRO, M.L.F.; CASTRO, M. S.; Estudo comparativo da metodologia ativa "gincana" nas modalidades presencial e à distância em curso de graduação de Farmácia. ABCS - Arquivos Brasileiros de Ciências da Saúde. 2015; 40 (3): $234-240$.

GUALBERTO, A.C.A; VICENTE, R. P. A inclusão de metodologias ativas na disciplina de deontologia farmacêutica - relato de experiência docente. Revista de Educação Meio Ambiente e Saúde. 2017; 7(2): 1-10.

JESUS, E.M.S.; SANTOS, D.V.; VIEIRA, M.L.C.; CARVALHO, A.A. Metodologias de ensino e os estilos de aprendizagem na graduação em farmácia: um estudo piloto. Revista Online de Política e Gestão Educacional. 2017; 21 (1): 621 - 639. Disponível em: https://periodicos.fclar.unesp.br/rpge/article/view/992. Acesso em: 22 de fevereiro de 2019.

LIMBERGER, J.B. Metodologias ativas de ensino-aprendizagem para educação farmacêutica: um relato de experiência. Interface- Comunicação Saúde Educação. 2013; 17(47): 969-75.Disponívelem:<http://www.scielo.br/scielo.php?pid=S1414-

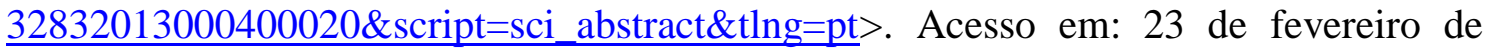
2019.

MARINI, D.C. Avaliação da Experiência de Estudantes de Farmácia no Componente Curricular de Farmacologia com a Utilização da Metodologia de Aprendizagem Baseada em Tarefas. Foco. 2013; 4(50): 89-110. Disponível em: $\langle$ http://www.scielo.br/pdf/icse/v15n36/aop3310.pdf $>$. Acesso em: 20 de fevereiro de 2019.

MARINI, D.C. Avaliação da experiência de estudantes de farmácia no componente curricular de farmacologia com a utilização da metodologia de aprendizagem baseada em tarefas. Foco. 2013; 4 (5): 89-110. 
SANTANA, C.A.; CUNHA, N.L.; SOARES, A.K.A. Avaliação discente sobre a metodologia de ensino baseado em problemas na disciplina de Farmacologia. Revista Brasileira de Farmácia. 2012; 93 (3): 337-340.

TONIETO, C.; FÁVERO, A.A. Contribuições da Filosofia de John Dewey para a educação: a democracia como credo pedagógico. In: IX ANPED SUL - SEMINÁRIO DEPESQUISA EM EDUCAÇÃO NA REGIÃO SUL, 9., 2012, Caxias do Sul. Anais. Caxias do Sul: UCS, 2012. 15p. Disponível em: 〈http://bit.ly/1L3pd2z>. Acesso em: 25 de fevereiro de 2018. 